\title{
Identification of Physical Transportation Infrastructure Vulnerable to Sea Level Rise
}

\author{
Frederick Bloetscher ${ }^{1}$, Thomas Romah ${ }^{1}$, Leonard Berry ${ }^{2}$, Nicole Hernandez Hammer ${ }^{3}$ \& Maria Abadal Cahill ${ }^{4}$ \\ ${ }^{1}$ Florida Atlantic University, Department of Civil, Environmental and Geomatics Engineering, FL, USA \\ ${ }^{2}$ Florida Center for Environmental Studies Co Director FAU Climate Change Initiative Florida Atlantic \\ University, FL, USA \\ ${ }^{3}$ Climate Change Initiative, Florida Atlantic University, Florida Center for Environmental Studies, FL, USA \\ ${ }^{4}$ Florida Department of Transportation, Office of Policy Planning, FL, USA \\ Correspondence: Frederick Bloetscher, Florida Atlantic University, Department of Civil, Environmental and \\ Geomatics Engineering, 777 Glades Rd. Boca Raton, FL 33431, USA. Tel: 1-239-250-2423. E-mail: \\ h2o_man@bellsouth.net
}

Received: October 25, 2012 Accepted: November 15, 2012 Online Published: November 27, 2012

doi:10.5539/jsd.v5n12p40 URL: http://dx.doi.org/10.5539/jsd.v5n12p40

\begin{abstract}
The objective of this research was developing a methodology for assessing the potential impacts of sea level rise (SLR) on Florida's state transportation infrastructure to assist the state with transportation planning. The proposed approach integrates the Florida Department of Transportation (FDOT) information system, satellite imagery, local roadway and hydrologic data with existing topographical and geographical data to generate SLR projections to facilitate $i$ ) the evaluation of current and projected SLR impacts on transportation infrastructure located along Florida's coastline and low-lying terrain areas, and ii) the identification of the physical transportation infrastructure components that are vulnerable given the United States Army Corps of Engineers' scenario-based methodology to project the timing of future low, intermediate and high rates of sea level change. A detailed case study in Dania Beach, Florida and a comparative example in Punta Gorda, Florida were used to evaluate the soundness of the methodology. Further research was performed to develop a preliminary evaluation of the impact of groundwater levels as an exacerbating factor with respect to sea level rise. Storm surge with SLR is a future, more difficult area of investigation.
\end{abstract}

Keywords: sustainable infrastructure, transportation, sea level rise

\section{Introduction}

Over the past 100 years, worldwide surface temperatures have increased at an unprecedented rate, contributing to warming of the oceans, melting ice fields and glaciers, altered precipitation patterns and other climatic effects (International Panel on Climate Change (IPCC), 2007). Rising temperatures lead to thermal expansion of the ocean and melting ice caps, both of which result in increased ocean levels (Vermeer \& Rahmsdorf, 2009; Jevrejeva et al., 2010), making Florida among the most vulnerable areas in the world for climate change due its coastal proximity and low elevation, especially southeast Florida (Organisation for Economic Co-Operation and Development (OECD), 2008). While the 2007 IPCC report on global scientific consensus regarding climate change stated that the "warming of the climate system is unequivocal, as is now evident from observations of increases in global average air and ocean temperatures, widespread melting of snow and ice, and rising global average sea level" (IPCC, 2007), Florida has more immediate needs for adaptation and mitigation strategies for low lying areas (Murley et al., 2009).

This project included a comprehensive literature review and analysis of SLR projections, studies, models and methodologies. Twelve different projections of SLR and its timing were reviewed, as was the Southeast Florida Regional Climate Compact (SFRCC, 2011) consensus projection recommended by its scientific working group. From the literature review and analysis, it was concluded that approximately $3 \mathrm{ft}$. of sea level rise by 2100 would a suitable scenario and time frame to illustrate the vulnerability assessment methodology presented in this article. Figure 1 was proposed by Heimlich et al. (2009) as a means to project sea level rise, given the needs for both planning ahead and reluctance to spend money too early. The results of Figure 1 match the US Army Corps of 
Engineer's methodology to derive scenarios of sea level change, which the SFRCC adopted the intermediate to high rates of SLR for years 2030 (3" to 7") and 2060 (9" to 24") as the consensus projection to guide future planning in Southeast Florida. As a result, these projections were used as a basis for SLR projections. It was noted that the mid-range level of 3 feet is critical for low-lying coastal areas like southeast Florida where over half the urban areas has elevations below 5 feet National Geodetic Vertical Datum of 1929 (NGVD), making it highly vulnerable to inundation since mean high tide is approximately 2 feet above mean tide (Bloetscher et al., 2010, 2012). As a result, water, sewer, stormwater and transportation infrastructure in low-lying areas could be compromised.

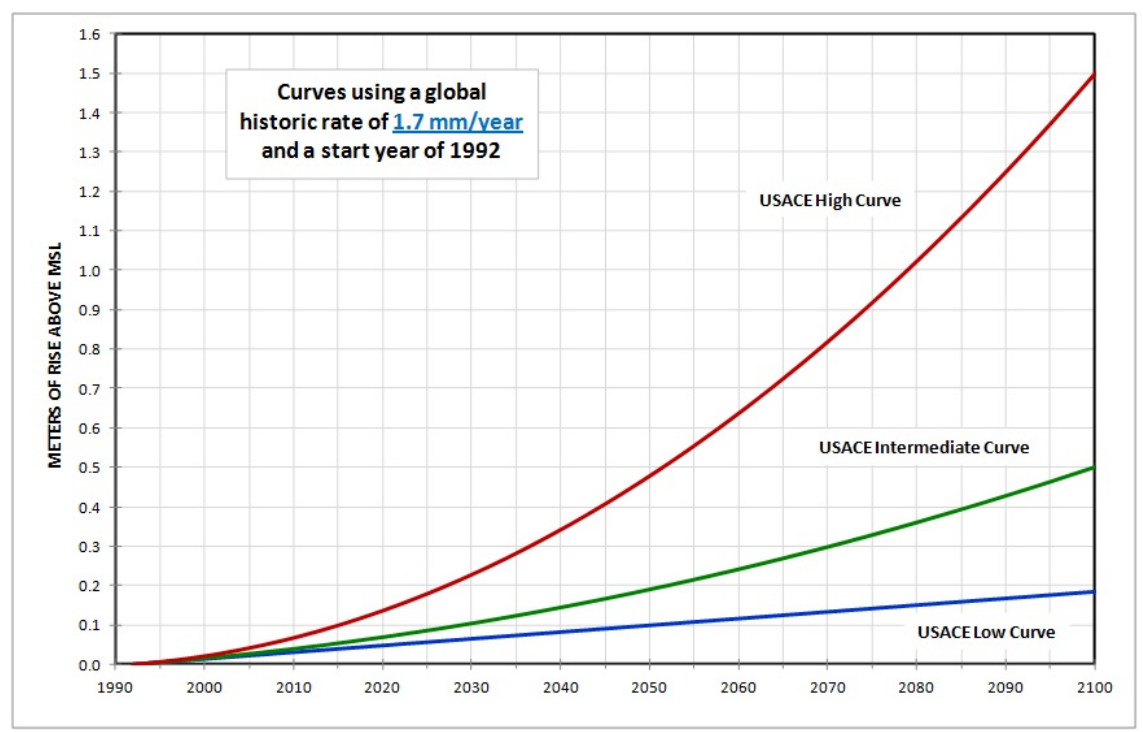

Figure 1. Graphic of sea level rise projections from the Army Corps of Engineers (http://www.corpsclimate.us/ccaceslcurves.cfm)

As sea level rises, access to roads, bridges, rail and rail transit could be at risk of flooding, causing the effects of SLR to spread indirectly throughout the entire transportation system, affecting the overall system performance. For example, the flooding of a critical road or facility access can cause a shifting of traffic flow causing congested conditions in other roadways. Since the roadway network would be unable to carry the traffic demand, the system would experience operational failure; as a result causing high travel times and delays. Moreover, the inundation of a critical access could cause transportation connectivity problems by blocking access to critical areas like ports or airports. Higher groundwater levels in low-lying areas compounds problem as stormwater management strategies may also become compromised.

Related to the transportation infrastructure is the related effectiveness of flood control and stormwater drainage systems for the transportation corridors. Road integrity relies on adequate drainage. The increased risk of severe flooding in Florida's low-lying terrain can adversely affect transportation infrastructures along the coastline; roads can be inundated and roadway beds can be damaged. Sea level rise will cause increased water table levels (Florida Department of Transportation (FDOT), 2012), as regional groundwater tables cannot exist naturally below mean high tide ( 2 feet in Florida). Adding 3 feet of SLR on top of groundwater would compound the risk of flooding in low-lying areas. Road bases below 5 feet NVGD would become saturated under this scenario, likely causing premature base failure. As soil storage capacity is diminished due to rising groundwater elevations associates with SLR, the potential for more frequently flooded roadways would likely damage pavements (FDOT, 2012). Figure 2 is the typical representation of the problem before and after sea level rise.

Figure 2a illustrates properly constructed FDOT roadways (note that many local roads do not meet these standards FDOT roadways are the main arteries for transportation as well as emergency evacuation routes a result, FDOT needed to identify vulnerable infrastructure and design engineering solutions to attenuate the risk. FDOT funded this research to develop a methodology for projecting future rates of SLR and to identify at-risk roadway sections throughout the state, using existing data sources and based on the development of case studies in southeast and southwest Florida. The results identified a protocol to identify vulnerable infrastructure and identified solutions that might be warranted depending on the situation (FDOT, 2012). 


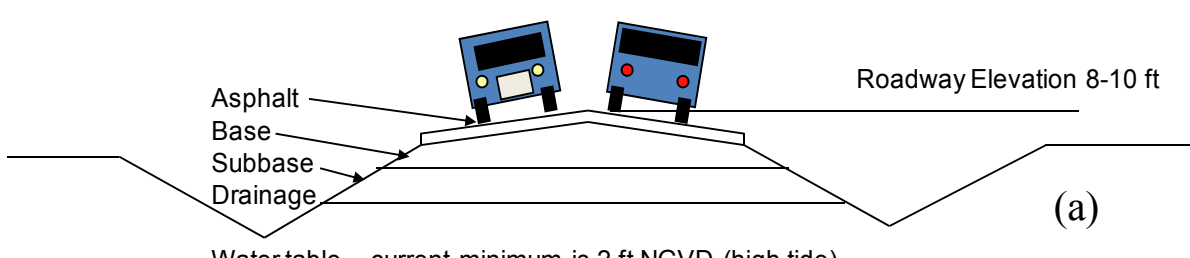

Water table - current minimum is $2 \mathrm{ft} \mathrm{NGVD} \mathrm{(high} \mathrm{tide)}$

\section{Current Base Condition for Low lying Roads}

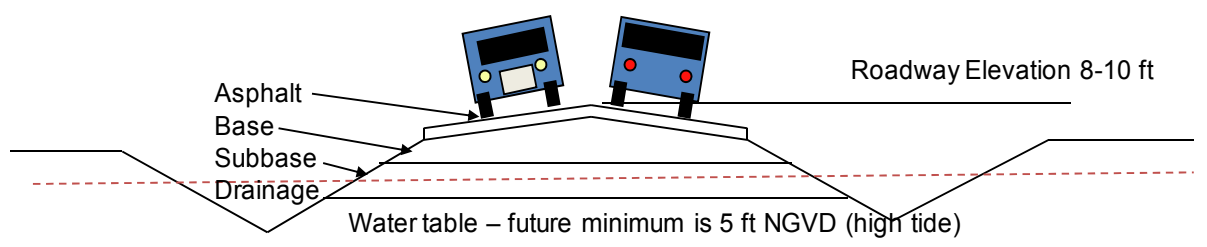

Future Condition for Low lying Roads

(b)

Figure 2a and b. Impact to roadbeds - base gets saturated (FDOT, 2012)

\section{Methodology}

The first step in protocol is to use agreed upon projections - as noted, this research recommended using the US Army Corps of Engineer's methodology and Heimlich et al. (2009) to generate scenarios of SLR. Using 1, 2, and $3 \mathrm{ft} \mathrm{SLR}$ scenarios, the second step of the methodology was to apply the vulnerability assessment methodology to identify segments for the Florida state roadways at a macro level that are potentially vulnerable to SLR at 2100 , including those that might be at risk of flooding (FDOT, 2012). The protocol uses geographic information system (GIS) and Light Detection and Ranging (LiDAR) data, plus a downscaling process that evaluates the vulnerability of transportation infrastructure to localized future rates of sea level change. The computer program ArcGIS was used as the base program to integrate data from a variety of sources for the evaluation. The concept refines the bathtub model approach used by J. L. Weiss and J. T. Overpeck at the University of Arizona at the University of Arizona, by applying it to the most accurate topographic and land use databases to identify vulnerable infrastructure (FDOT, 2012). The procedure to identify physical transportation infrastructure along Florida's coastline and low-lying terrain vulnerable to SLR and surge storms was divided into the following four parts: 1) State SLR projections - preliminary identification of all state roadways vulnerable to SLR by 2100 on a statewide basis based on a 3 foot sea level rise scenario; 2) Regional SLR projections - evaluation of the current and projected 2100 topographical conditions of vulnerable roadway sections using lower resolution Light Detecting Radar (LiDAR) data (realizing this is the only data available for inland areas); 3) Localized SLR projections - evaluation of projected 2100 topographical conditions of vulnerable roadway sections using high resolution LiDAR data (+/- 6-9 in vertical accuracy); and 4) On-the-ground (OTG) evaluation - verification of roadways vulnerability using construction drawings, site visits and topographic survey data (FDOT, 2012). A flow chart of this downscale evaluation procedure is shown in Figure 3. It should be noted that this approach is not limited to a particular SLR projection; the methodology can be applied to other scenarios depending on the vertical accuracy of the LiDAR data. 


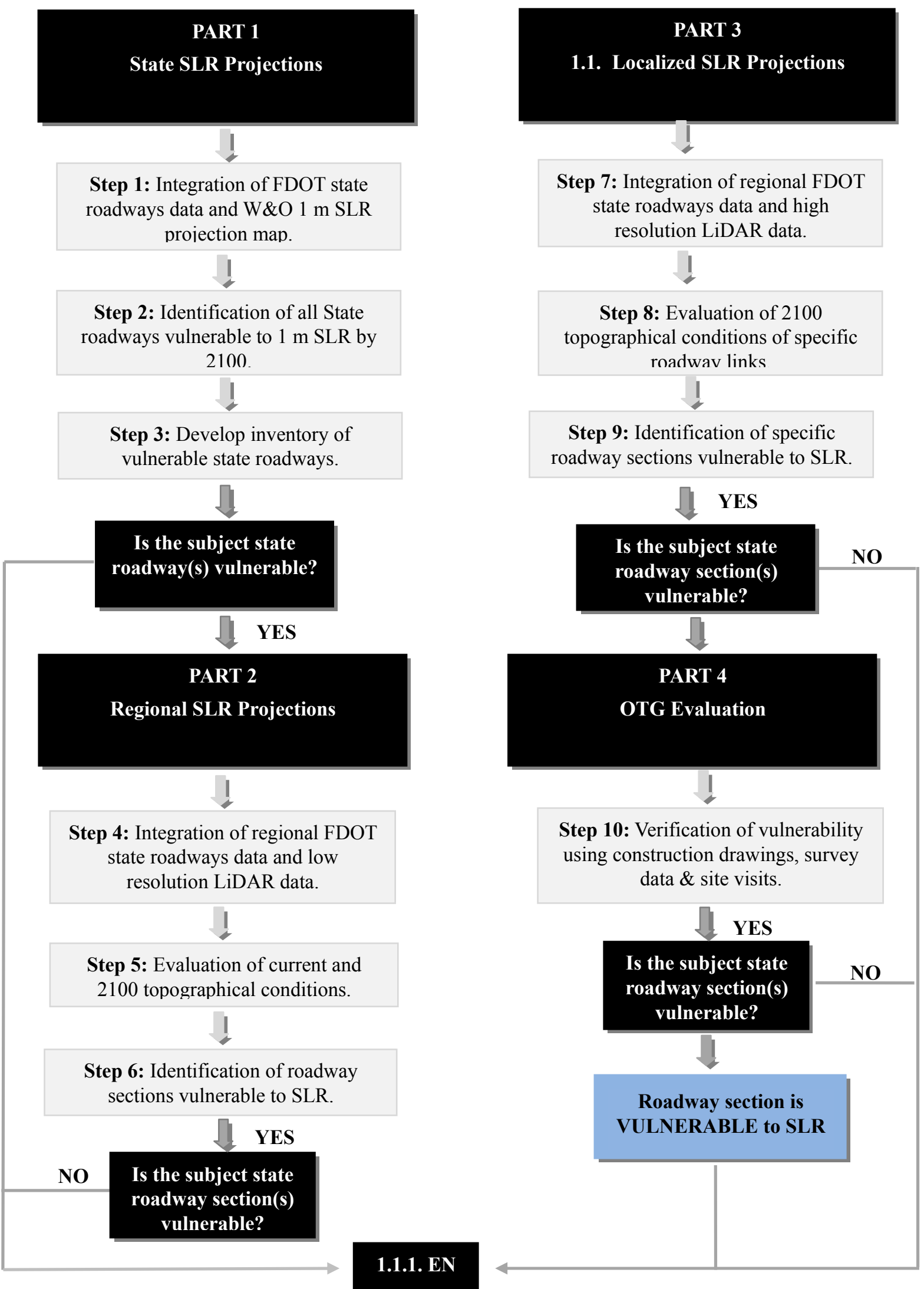

Figure 3. Flow chart of the procedure developed for the identification of vulnerable state road sections (FDOT, 2012) 
The next step was integration of the FDOT Unified Base Map Repository (UBR) and the Strategic Intermodal System (SIS) database and the $1 \mathrm{~m}(3.28 \mathrm{ft})$ SLR projection map from Weiss Overpeck to identify areas where the two mapping systems overlapped (the Weiss and Overpeck layer was provided by Dr. Weiss). Two areas were noted - those identified as being below 3 feet, and the location of FDOT infrastructure. As noted previously, the 5 foot elevation would indicate potential coastal inundation resulting from groundwater and sea level rising concurrently, so every roadway falling in the zone where the two layers coincided, were considered potentially vulnerable (FDOT, 2012). From this map, state-wide spreadsheets of all vulnerable roads were developed from GIS mapping of each segment of road. However, this is a preliminary identification and does not enough detail to determine which roadways actually are vulnerable.

The potentially vulnerable state road sections were extracted (clipped) as a new shape file in ArcGIS. Using the clipped state roads shape file, a new map is created and magnified for sections that fall within the area of interest using low resolution and high resolution LiDAR maps (step 2). If a section of a road previously identified as potentially vulnerable is within the hazard zone, it is considered vulnerable, and the inventory matrix is updated. Otherwise the section is marked as a conflicting segment.

Once roadway segments that are potentially vulnerable to SLR are identified, step 3 was to evaluate the roadways with more detailed topographic information. Multiple sources of elevation data for the state of Florida were identified and are listed in Table 1. The topographical data repository sources are organized by the following categories: national, state, and other (FDOT, 2012).

In general, three main data types, Topographic Contour Maps (USGS and others), Digital Elevation Maps (DEM), and Light Detection and Ranging (LiDAR), were used in the next evaluation steps. After evaluating the different types of topographic data available for Florida, LiDAR data was found to be the most appropriate format for this methodology. LiDAR was selected primarily because of its high vertical accuracy and the availability of significant areas of coverage. Although 2 foot contour information is available for most parts of the state, it does not compare with the level of accuracy provided by LiDAR information. However the accuracy of LiDAR data can also vary (FDOT, 2012):

- Low resolution LiDAR is 1 arc, which has a vertical accuracy of $+/-7$ to 15 meters, which is not satisfactory for Climate Change modeling. Low resolution LiDAR data was not used in this study.

- Medium Resolution LiDAR is $1 / 3$ and 1/9 arc. The $1 / 3$ arc has 7 meter vertical accuracy, which is not sufficient. The 1/9 arc data is the same 1 meter vertical accuracy as that in Weiss and Overpeck maps and is potentially useful in shape files.

- High Resolution LiDAR has a vertical accuracy of 7 inches, which is very useful. The disadvantage is large file size. For the case of Dania Beach, a small area of $4 \times 4$ miles (3-4 files) required 2 hours to process the data. The Florida Keys ( $>200$ files) required 24 computing hours.

The LiDAR data format used was the American Standard Code for Information Interchange (ASCII). This data format is easily handled by ArcGIS software. The ASCII format is comprised of the raw Laser (LAS) LiDAR data type format, translated into a geographically referenced X, Y, Z global coordinate plane system (FDOT, 2012). Of the different topographical data repository sources, the National Oceanic and Atmospheric Administration (NOAA) offered the data natively in ASCII format.

The LiDAR data needs to be corrected for datum. Once completed the geographically referenced roadway system was imported into ArcGIS and different incremental elevation heights and colors can be selected by the user. Shades of blue were used to inundation areas (deeper color = deeper water). Although ArcGIS allows the breakdown of elevation heights into fractional inch increments, it is important to recognize the limitations of the source data and how it is collected (FDOT, 2012). 
Table 1. Inventory of topographical data repository sources (FDOT, 2012)

\begin{tabular}{|c|c|c|}
\hline Data Source & $\begin{array}{l}\text { MEANING OF ACRONYM (Organization) } \\
\text { NATIONAL }\end{array}$ & $\begin{array}{c}\text { Relevant Data } \\
\text { Available }\end{array}$ \\
\hline USACE & United States Army Corps of Engineers & $*$ \\
\hline USGS & United States Geological Survey & YES \\
\hline USFWS & United States Fish and Wildlife Services & YES \\
\hline NOAA & National Oceanographic and Atmospheric Administration & YES \\
\hline FAA & Federal Aviation Administration & YES \\
\hline USDA & United States Department of Agriculture & YES \\
\hline FEMA & Federal Emergency Management Agency & NO \\
\hline NPS & National Park Service & NO \\
\hline NRCS & National Resource Conservation Service & NO \\
\hline USEPA & United States Environmental Protection Agency & NO \\
\hline \multicolumn{3}{|c|}{ STATE } \\
\hline FWRI & Fish and Wildlife Research Institute & YES \\
\hline FDEP & Florida Department of Environmental Protection & YES \\
\hline FDOT & Florida Department Of Transportation & YES \\
\hline FREAC & Florida Resources and Environmental Analysis Center (FSU) & YES \\
\hline SWFRPC & Southwest Florida Regional Planning Council & YES \\
\hline NWFWMD & Northwest Florida Water Management District & YES \\
\hline FDEM & Florida Department of Emergency Management & $* *$ \\
\hline SFWMD & South Florida Water Management District & YES \\
\hline SJRWMD & St. Johns River Water Management District & YES \\
\hline SWFWMD & Southwest Florida Water Management District & YES \\
\hline FDOF & Florida Division Of Forestry & NO \\
\hline FCFWRU & Florida Cooperative Fish and Wildlife Research Unit & NO \\
\hline FNAI & Florida Natural Areas Inventory & NO \\
\hline \multicolumn{3}{|c|}{ OTHER } \\
\hline GEOPLAN & FGDL Geoplan Center & YES \\
\hline BTS & Bureau of Transportation Statistics & YES \\
\hline Counties & Individual County government GIS departments & YES \\
\hline \multirow[t]{3}{*}{ Universities } & State Universities ( FSU and FIU) & YES \\
\hline & National Research Council & NO \\
\hline & Metropolitan Planning Organization & NO \\
\hline
\end{tabular}

*Have not been able to contact to source to access available information.

** FDEM administers topography information but does not act as a publisher or repository location. Updated $10 / 21 / 2010$.

\subsection{Limitations of LiDAR}

LiDAR reconnaissance planes bounce signals off points called posts that are coordinated in a grid pattern. Because the information is collected in a non-consecutive point system, assumptions and interpretation of the elevation between posts are made by software (FDOT, 2012; NOAA, 2010). Additionally raw LiDAR has to be converted into bare earth elevations to account for posts that reflect off objects such as vegetation that do not indicate the actual ground elevation. Different datums may be used so interpretation of data is involved that affects the vertical accuracy of the collected data, limiting the reliability of the data's use for small increments (NOAA, 2010; 2010a). It should also be noted that the groundwater table was assumed to be flat.

\subsection{Method Illustration}

The protocol seems complicated, but it is mostly a data integration exercise. The eastern portion of Dania Beach, a low-lying area of southeast Florida adjourning the coast, is used to illustrate this methodology. Most of this 
area of Dania Beach area is below 5 feet above mean sea level. As shown in Figure 4, visual inspection of the Weiss and Overpeck map identifies vulnerable state roads: US A1A, Griffin Road., US 1 (Federal Highway), Stirling Road and Sheridan Street (cross-hatched).

Figure 5 shows the high resolution LiDAR data result for Dania Beach. Vulnerable roads below the elevation of the projected SLR were identified visually. Various shades of blue are used for elevations under 5 feet. Any area that is vulnerable appears in a shade of blue. Green is used for areas between 5 and 10 feet above sea level. Road bases in these areas may become vulnerable to saturation as sea level rise progresses, as explained previously. After using high resolution LiDAR, more detailed on-the-ground (OTG) evaluations can be conducted. OTG verification may identify borderline areas that might be subject to inundation. In this case FDOT roadway plans were used to verify the LiDAR results.

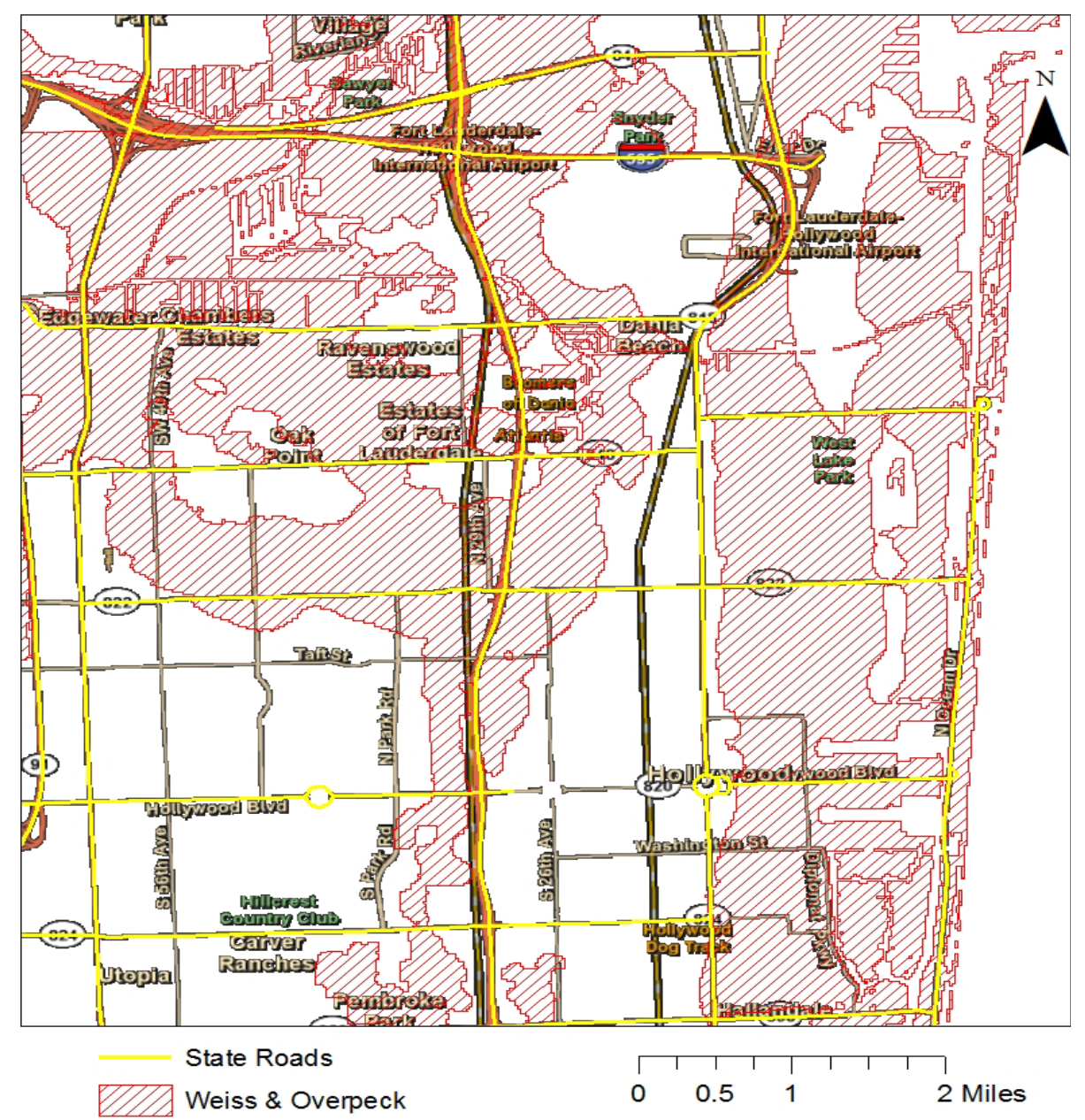

Figure 4. Most of the Dania Beach area has elevations of less than 5 feet above sea level - Weiss and Overpeck overlay in hatching (FDOT, 2012) 


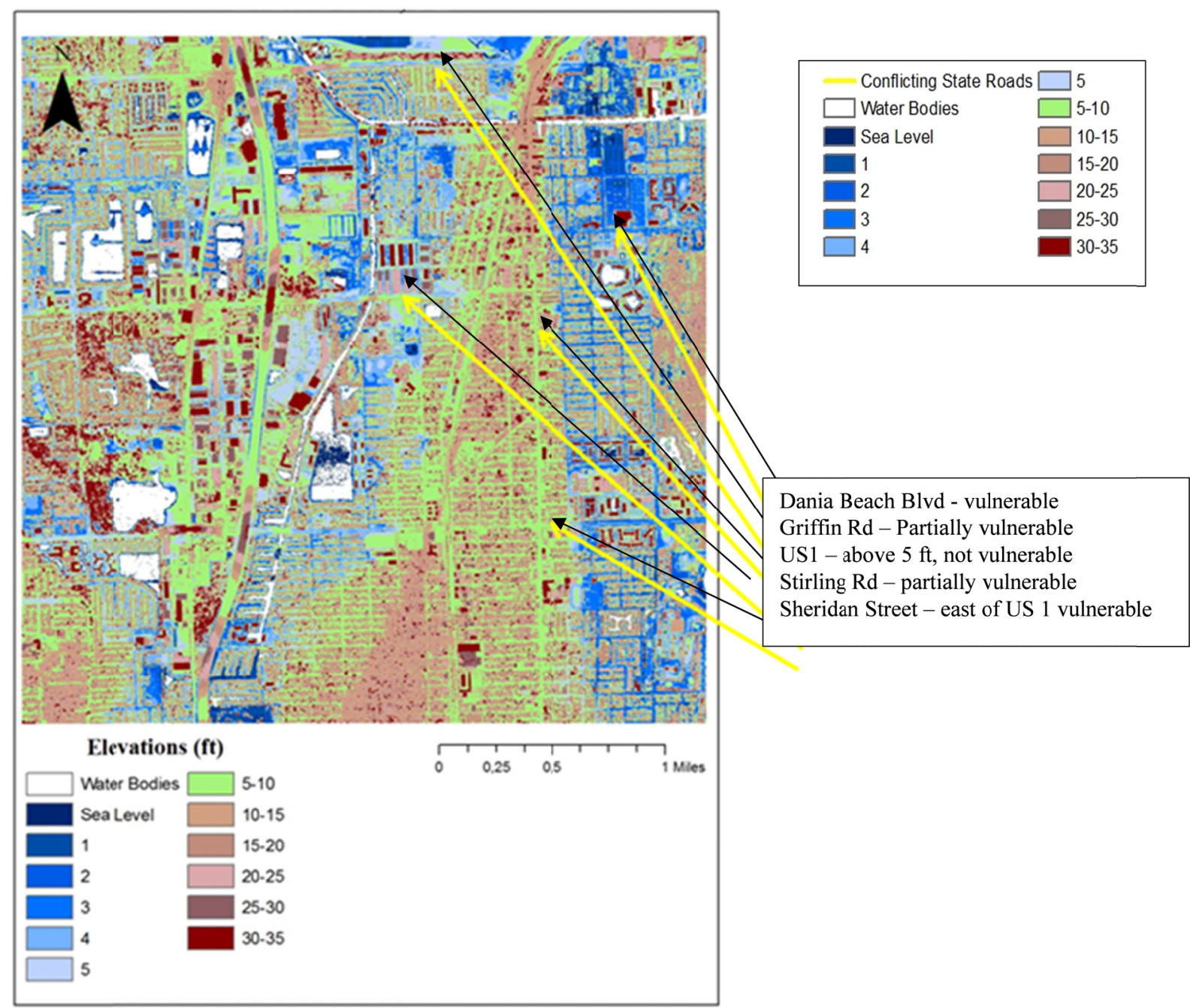

Figure 5. Dania beach overlay map using high resolution LiDAR Data (7" in vertical accuracy) (FDOT, 2012)

To confirm the methodology, another, area of the state extensively studied by Florida State University (FSU) was evaluated: Punta Gorda. Figure 6 compares our methodology for downtown Punta Gorda on the west coast of Florida with that of FSU (FDOT, 2012). The LiDAR method confirms the FSU findings, while providing significantly more detail on the vulnerable roadway infrastructure. It is the local streets that are vulnerable, not I-75 or US 41.

Table 2. Summary of Dania Beach roads based on methodology (by step) (FDOT, 2012)

\begin{tabular}{lccccc}
\hline \multicolumn{1}{c}{ State Road } & \multicolumn{2}{c}{ Roadway Vulnerability Evaluation } \\
& $\begin{array}{c}\text { W\&O map 1 } \\
\text { m SLR Map }\end{array}$ & $\begin{array}{c}\text { Localized } \\
\text { W\&O Map } \\
\text { (Blow Up) }\end{array}$ & $\begin{array}{c}\text { Medium } \\
\text { Resolution } \\
\text { LiDAR }\end{array}$ & $\begin{array}{c}\text { High } \\
\text { Resolution } \\
\text { LiDAR }\end{array}$ & OTG \\
\hline US 1 (Federal Highway) & $\mathrm{x}$ & $\mathrm{x}$ & $\mathrm{x}$ & $\mathrm{x}$ & $\mathrm{x}$ \\
US A1A (Dania Beach Blvd.) & $\mathrm{x}$ & $\mathrm{x}$ & $\mathrm{x}$ & $\mathrm{x}$ & \\
Griffin Road & $\mathrm{x}$ & $\mathrm{x}$ & partial & partial & partial \\
Stirling Road & $\mathrm{x}$ & $\mathrm{x}$ & partial & partial & partial \\
Sheridan Street & $\mathrm{x}$ & $\mathrm{x}$ & & & \\
\hline
\end{tabular}



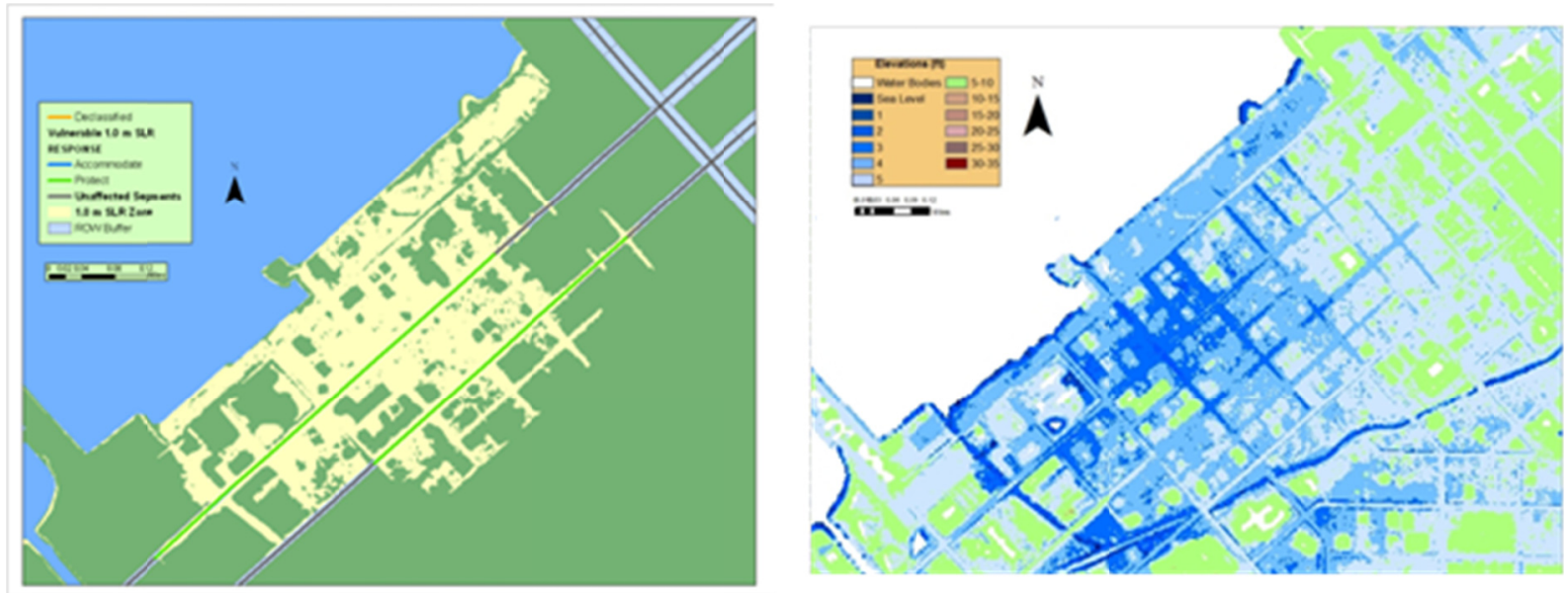

Figure 6. Downtown Punta Gorda area comparing the FSU and FAU LiDAR maps. The LiDAR map provides more elevation information than in Chapin's map. Both maps show roughly the same areas inundated with SLR downtown. However, maps created in this research show that there are areas south of downtown that are also potentially vulnerable along the canals (FDOT, 2012)

\subsection{Effect of Groundwater}

The LiDAR project creates what is commonly referred to as a bathtub scenario, but bathtub models do not necessarily conform with sea level rise where groundwater may be a potential issue. A typical bathtub model only considers the elevation of the ground above a reference level for determining SLR vulnerability. A missing factor however, is that inland groundwater builds up due to friction while traveling toward the low lying hydraulic base (to the sea). Hence the groundwater table increases going away from the coast (it is not flat). The buildup of water creates a scenario that is not captured in the bathtub model in that the soil storage capacity is reduced and in some cases permanent inundation will occur in regions prior to when it would be expected to occur under a typical bathtub model. As a result, the sea level rise (SLR) model for Miami-Dade, and Broward County was designed to take into account the possible effects the groundwater table can have on determining SLR inundation in low elevation areas, especially in inland areas.

The first step for updating the model with sea level rise was incorporating a groundwater surface elevation map into the model. Data points for determining the ground water surface was created by using the historical USGS well site records for groundwater levels. The results of the database showed large seasonal swings in the groundwater table levels as shown in Figure 8, which necessitated three separate SLR model scenarios to be evaluated given different groundwater conditions.

The determined levels consisted of the fiftieth percentile monthly average values for June and October which showed the low level and high level extremes respectively. The final model variant was an extremes model based on the highest median monthly value for the month of October. The final inundation model was created in GIS by subtracting the ground water surface models from the digital elevation model as shown in Figure 8. Here values shown as negative indicate inundation and positive values indicate the distance between the ground water surface and ground surface elevation. Different SLR scenarios were created by creating modified ground water surface grids that represented the different combinations of initial ground water surfaces with added incremental sea level rise values considered. The results show a continuous increase in the vulnerability of the transportation network as SLR values increase. The results further illustrate that SLR vulnerability is not just a coastal feature for the study region in that the inundation is shown to move from inland areas towards the eastern coast of Florida. 


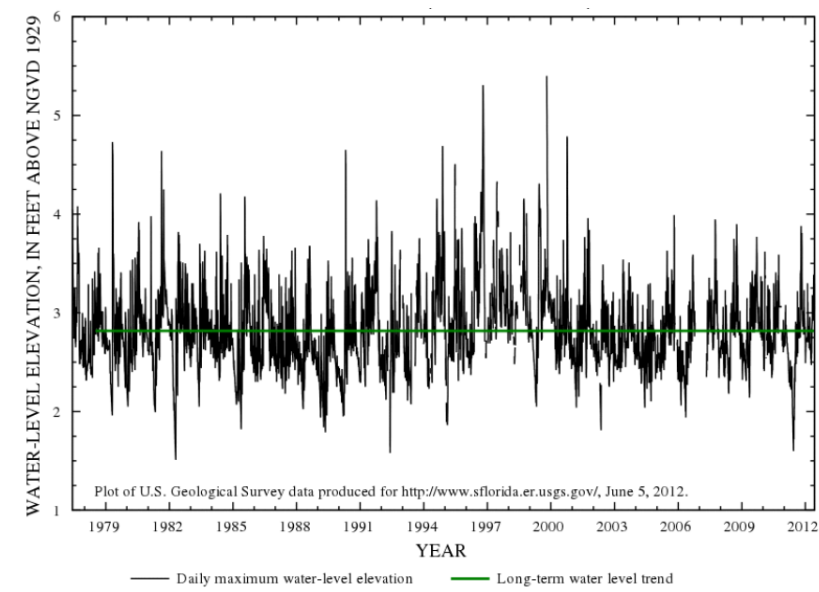

Figure 7. Groundwater levels at USGS station G970 (www.usgs.com)
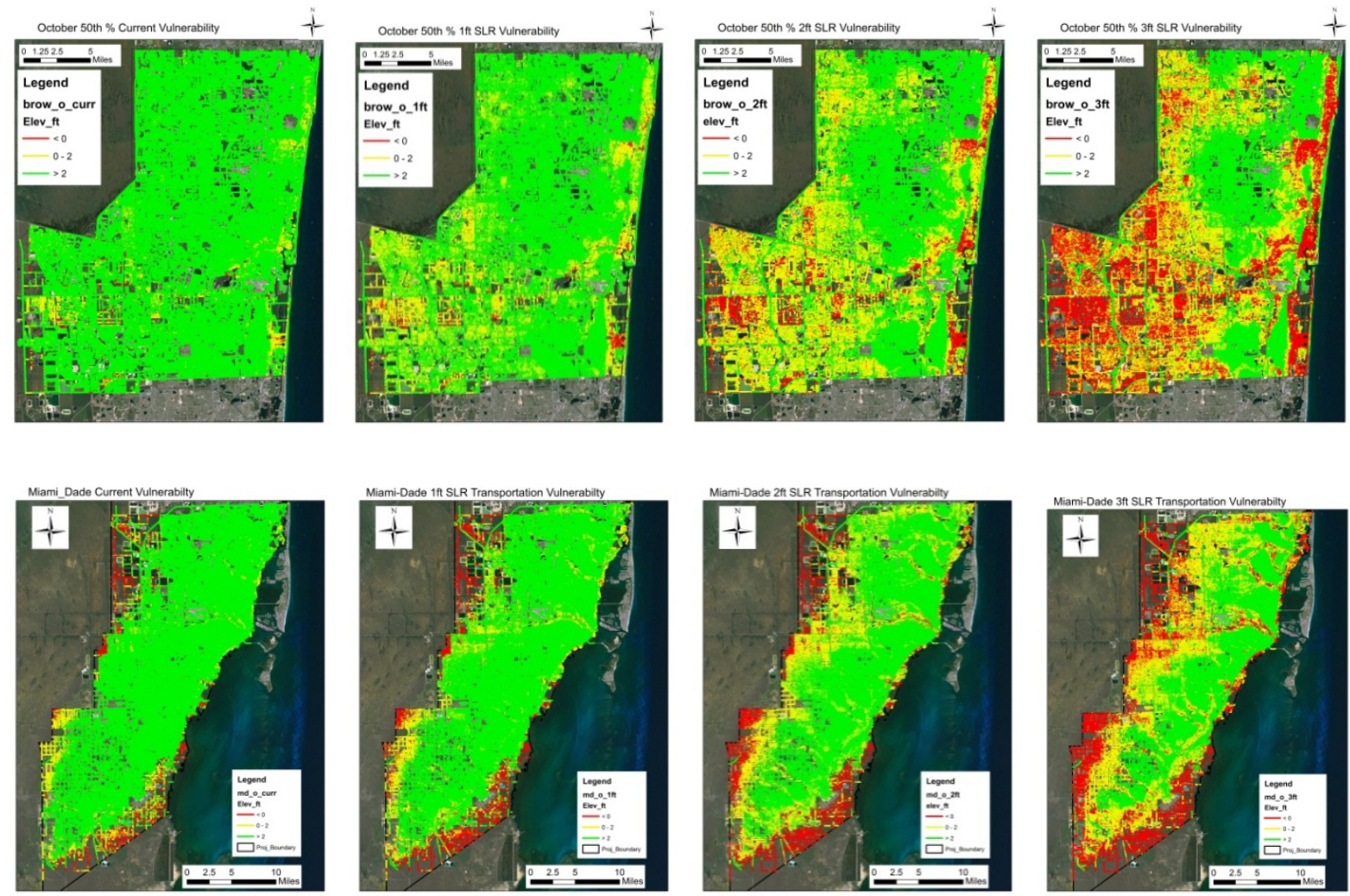

Figure 8. Miami-Dade and Broward County inundation results

\section{Discussion}

Based on the results of Figure 8, up to $10 \%$ of southeast Florida's roadways as being potentially vulnerable to sea level rise from a bathtub model perspective and nearly 5 percent of the whole state may be vulnerable. However, much larger areas may be inundated in low lying areas where the groundwater table may concurrently rise. As a result, in southeast Florida for example, a much larger percent of roadways, especially inland, may be subject to flooding groundwater that results from sea level rise.

In either case, there is a need to prioritize where funds are spent on transportation infrastructure and other major investments. The vulnerability of transportation infrastructure will require the design of more resistant and adaptive infrastructure and network systems, which in turn, would involve the development of new performance measures for assessing the ability of transportation infrastructure (e.g., roadways, bridges, rail, sea ports, airports) 
to adapt to sea level rise; enhanced design standards and guidelines for design and construction of resilient transportation facilities, retrofitting, material protective measures, rehabilitation, and in some cases, relocation of the facility will be necessary to accommodate SLR impacts. Groundwater is expected to have a significant impact on flooding in these low-lying areas as a result of the loss of soil storage capacity, which has not been the focus of many planning efforts. Catastrophic flooding would be expected during heavy rain events because there is nowhere for the runoff to go.

Because it is critical to protect the roadway base, all efforts should begin with providing the base with adequate drainage systems to meet future conditions. At present, most base courses are installed above the water table. As long as the base stays dry, the roadway surface will remain stable. As soon as the base is saturated, the roadway can deteriorate. As water levels rise, wellpoint systems may need to be installed for more permanent drainage. However, wellpoint water is usually turbid containing sand, other particles, and contaminants from runoff, which requires an offsite discharge zone. Treatment areas for removal of particulates and sand will also be required, requiring additional area for discharge purposes. Wellpoint pump stations need to be regularly spaced along the affected roadway. As a result a series of pump stations might be needed for every mile of roadway since typical dewatering systems are generally confined to areas less than 500 feet in length. Since wellpoints do not function in flood conditions, additional drainage measures must be taken to address wellpoint failure during heavy rainfall events. The costs for such systems could exceed $\$ 1$ million per lane mile based on data gathered by the project team.

FDOT and most Florida municipalities rely heavily on exfiltration trenches or French drains. These systems work because the perforated piping is located above the water table. They cease to function if they are located below the water table. Exfiltration systems in low-lying areas will cease to work as they become submerged. Future storm water systems should be designed like sanitary sewers with tight piping, minimal allowances for infiltration and adequately sized pumping stations with permitted discharge points and means for associated treatment. Stormwater gravity wells are a useful option where saltwater underlies the surface. Drainage wells along the southeast Florida coast can drain 1 MGD under certain conditions. However as sea level rises, the potential for pumping will be altered. Wells of this type generally cost about $\$ 150,000$ each for a 24 inch diameter well, based on recent bid reviews. They also require splitter boxes and filters to remove solids, regular inspections and regular maintenance increasing transportation system budgets.

For low-lying areas, elevating roads may be an option. However, this option comes with two significant issues: roadway elevations and impacts on adjacent properties. Roadways are designed for 50 to 100 -years service life. As a result, transportation agencies should design roadway bases to be above the mean high water table of $5 \mathrm{ft}$ NGVD. Such roads would likely have surface elevations at or above $8 \mathrm{ft} \mathrm{NGVD,} \mathrm{well} \mathrm{above} \mathrm{many} \mathrm{of} \mathrm{today's}$ low lying roads and in many cases above the finished floors of adjacent properties, and they will act as dams unless provisions, such as culverts or pumps, are made for horizontal movement of water, creating a potential storm water runoff concern. Raising roadways is expected to exceed the cost of new roads. The authors estimate $\$ 1$ million per lane mile, plus the additional right-of-way costs, based on a review of recent FDOT bids. In addition, sanitary sewers, water mains and other utilities underlie these pavements, and will also required relocation at additional costs. Elevating the roads would require manholes to be reconstructed, water lines replaced and most other underground utilities replaced. The costs for these improvements are estimated at roughly $\$ 4$ million per mile of roadway.

A final option is abandonment of roadways, which may be appropriate for a number of situations. The roadways would be abandoned to underlying local governments, who would be responsible for the infrastructure. However this would only be done where the roadway no longer serves its purpose or the adjacent properties are being abandoned. Where these displaced residents go is uncertain although migration and displacement of residents could be a domino.

\section{Conclusions}

The US Army Corps of Engineers has specified that any coast or near-coast projects must include consideration of sea level rise. Therefore, transportation agencies should include the impact of sea level rise into all long-range planning. The methodology developed herein recommends use of US Army Corps of Engineers scenarios for sea level rise, extrapolated to 2100 by Heimlich et al. (2009), integrated with LiDAR, topographic, groundwater level and aerial photographic maps to identify potentially vulnerable roadway infrastructure across the state. Overlaying high resolution LiDAR data onto a base map enabled creation of mapping tools to evaluate potentially vulnerable infrastructure. This methodology is shown to be effective and generally accurate, once correction factors were applied. Testing the protocol on several low-lying areas of the state to determine the 
extent of roadway infrastructure that might be vulnerable was successful. Drilldown efforts were used to identify "potentially vulnerable", and thereafter "vulnerable" infrastructure. LiDAR and ground-truthing was used to verify the accuracy of the protocol.

Vulnerability is highly dependent on local conditions in different parts of the Florida coast; vulnerability analysis can be achieved by the drilldown methodology employed in this study. Once results are understood, it is important to incorporate adaptive management processes into the planning as more information becomes available. Estimates of what these adaptive processes may cost was included for planning purposes. Priorities and sequence are local issues that need local input.

\section{References}

Bloetscher, F., Heimlich, B. N., \& Romah, T. (2011). Counteracting the Effects of Sea Level Rise in Southeast Florida. Journal of Environmental Science and Engineering, 5(11), 1507-1525.

Bloetscher, F., Meeroff, D. E., Heimlich, B. N., Brown, B., \& Loucraft, M. (2010). Improving the Resilience against the Impacts of Climate Change. Journal American Water Works Association, 102(11), 36-46.

Bloetscher, F., Meeroff, D. E., \& Heimlich, B. N. (2009). Improving the Resilience of a Municipal Water Utility against the Likely Impacts of Climate Change. A Case Study: City of Pompano Beach Water Utility, Florida Atlantic University, November 2009. Retrieved from http://www.ces.fau.edu/files/projects/climate_change/PompanoBeachWater_CaseStudy.pdf

FDOT. (2012). BDK79 977-01 Development of a Methodology for the Assessment of Sea Level Rise Impacts on Florida's Transportation Modes and Infrastructure, Summary [PDF - $470 \mathrm{~KB}$ ], Final Report [PDF 13,326 KB]. Retrieved from http://www.dot.state.fl.us/research-center/Completed_Planning.shtm

Heimlich, B. N., Bloetscher, F., Meeroff, D. E., \& Murley, J. (2009). Southeast Florida's Resilient Water Resources: Adaptation to Sea Level Rise and Other Impacts of Climate Change. Boca Raton(FL): Florida Atlantic University: Center for Urban and Environmental Solutions, Department of Civil Engineering, Environmental, and Geomatics Engineering. Retrieved from http://www.ces.fau.edu/files/projects/climate_change/SE_Florida_Resilient_Water_Resources.pdf

IPCC. (2007). Climate Change 2007: The Physical Science Basis. Contribution of Working Group I to the Fourth Assessment Report of the Intergovernmental Panel on Climate Change. In S. D. Solomon, M. Qin, Z. Manning, M. Chen, K. B. Marquis, M. T. Averyt, \& H. L. Miller (eds.). Cambridge, United Kingdom: Cambridge University Press \& New York, NY, USA.

Jevrejeva, S., Moore, J. C., \& Grinsted, A. (2010). How will sea level respond to changes in natural and anthropogenic forcings by 2100? Geophysical Research Letters, 37, L07703. http://dx.doi.org/10.1029/2010GL042947

Murley, H., \& Bollman. (2008). Florida's Resilient Coasts: a State Policy Framework for Adaptation to Climate Change. Florida Atlantic University, May 2008. Retrieved from http://www.ces.fau.edu/files/projects/climate_change/Fl_ResilientCoast.pdf

National Oceanic and Atmospheric Administration (NOAA) Coastal Service Center. (2010). Mapping Inundation Uncertainty. Retrieved January from http://www.csc.noaa.gov/slr/viewer/assets/pdfs/Elevation_Mapping_Confidence_Methods.pdf

National Oceanic and Atmospheric Administration (NOAA) National Ocean Service (NOS). (2010a). Technical Considerations for the Use of Geospatial Data in Sea Level Change Mapping and Assessment. NOAA NOS Technical Report. Silver Springs, M.

OECD. (2008). Ranking Port Cities with High Exposure and Vulnerability to Climate Extremes: Exposure Estimates. Organisation for Economic Co-Operation and Development, OECD Publishing.

Southeast Florida Regional Climate Change Compact (SFRCC) Inundation Mapping and Vulnerability Assessment Work Group. (2011). Analysis of the Vulnerability of Southeast Florida to Sea Level Rise.

Vermeer, M., \& Rahmstorf, S. (2009). Global sea level linked to global temperature. PNAS, 106(51), 21527-21532. http://dx.doi.org/10.1073/pnas.0907765106 